\title{
Confusion matrices
}

\begin{tabular}{|c|c|c|c|}
\hline & \multicolumn{2}{|c|}{ Expert Gold Standard } \\
\hline & & Snow & No Snow \\
\hline \multirow{2}{*}{ Crowd } & Snow & 453 & 11 \\
\hline & No Snow & 5 & 1328 \\
\hline
\end{tabular}

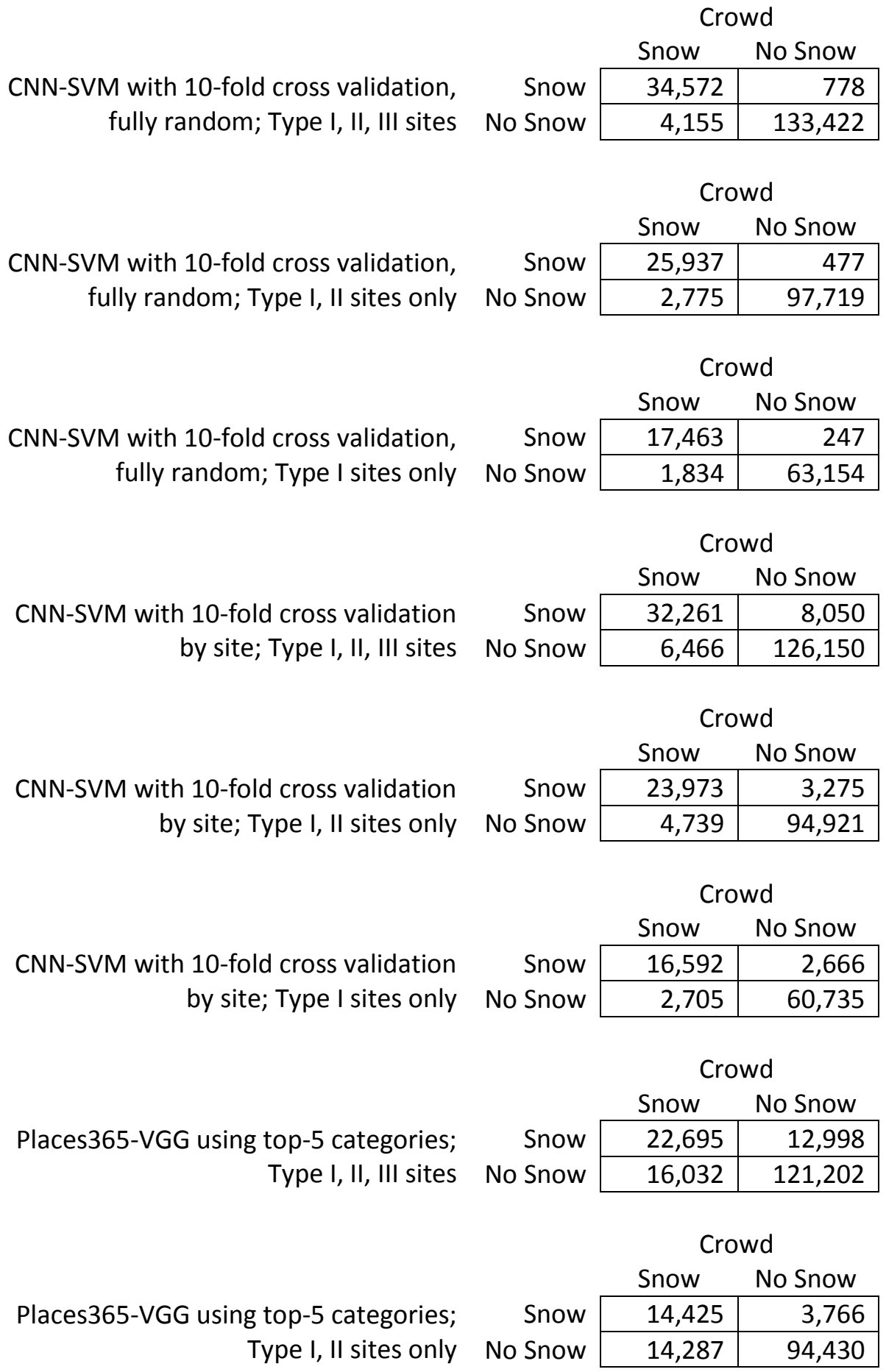




\begin{tabular}{|c|c|c|c|c|c|c|}
\hline & & & & & $\mathrm{Crc}$ & \\
\hline & & & & & Snow & No Snow \\
\hline Place & s365-VGG & ing top-5 & ategories; & Snow & 9,617 & 2,340 \\
\hline & & Type & sites only & No Snow & 9,680 & 61,061 \\
\hline & & Expert Gol & Standard & & & \\
\hline & & Snow & No Snow & & & \\
\hline & Snow & 143 & 15 & & & \\
\hline IVIODIS & No Snow & 32 & 854 & & & \\
\hline & & $\mathrm{CrC}$ & wd & & & \\
\hline & & Snow & No Snow & & & \\
\hline & Snow & 11,089 & 2,802 & & & \\
\hline MODIS & No Snow & 3,381 & 78,879 & & & \\
\hline & & $\begin{array}{l}\text { Best CI } \\
\text { (Type I s } \\
\text { fully ran }\end{array}$ & $\begin{array}{l}\text { N-SVM } \\
\text { tes only, } \\
\text { lomized) }\end{array}$ & & & \\
\hline & & Snow & No Snow & & & \\
\hline & Snow & 4,969 & 1,911 & & & \\
\hline IVIODIS & No Snow & 850 & 36,780 & & & \\
\hline
\end{tabular}

